\title{
Effects of endogenous sex hormones on lung function and symptom control in adolescents with asthma
}

Mark D. DeBoer ${ }^{1}$, Brenda R. Phillips², David T. Mauger², Joe Zein ${ }^{3}$, Serpil C. Erzurum³, Anne M. Fitzpatrick4, Benjamin M. Gaston ${ }^{5}$, Ross Myers ${ }^{5}$, Kristie R. Ross ${ }^{5}$, James Chmiel ${ }^{5}$, Min Jie Lee ${ }^{4}$, John V. Fahy ${ }^{6}$, Michael Peters ${ }^{6}$, Ngoc P. Ly ${ }^{6}$, Sally E. Wenzel ${ }^{7}$, Merritt L. Fajt ${ }^{7}$, Fernando Holguin', Wendy C. Moore ${ }^{8}$, Stephen P. Peters ${ }^{8}$, Deborah Meyers ${ }^{8}$, Eugene R. Bleecker ${ }^{8}$, Mario Castro $^{9}$, Andrea M. Coverstone ${ }^{9}$, Leonard B. Bacharier ${ }^{9}$, Nizar N. Jarjour ${ }^{10}$, Ronald L. Sorkness ${ }^{10}$, Sima Ramratnam ${ }^{10}$, Anne-Marie Irani ${ }^{11}$, Elliot Israel ${ }^{12}$, Bruce Levy ${ }^{12}$, Wanda Phipatanakul ${ }^{12}$, Jonathan M. Gaffin ${ }^{12}$ and W. Gerald Teague ${ }^{1 *}$

\section{Abstract}

Background: Although pre-puberty asthma is more prevalent in males, after puberty through middle-age, asthma is more prevalent in females. The surge of sex hormones with puberty might explain this gender switch.

Methods: To examine the effects of sex hormones on lung function and symptoms with puberty, Tanner stage was assessed in 187 children 6-18 years of age (59\% severe) enrolled in the NIH/NHLBI Severe Asthma Research Program (SARP). The effects of circulating sex hormones ( $n=68$; testosterone, dehydroepiandrosterone sulfate (DHEA-S), estrogen, and progesterone) on lung function and 4 week symptom control (ACQ6) in cross-section were tested by linear regression.

Results: From pre-/early to late puberty, lung function did not change significantly but ACQ6 scores improved in males with severe asthma. By contrast females had lower post-BD FEV $1 \%$ and FVC\% and worse ACQ6 scores with late puberty assessed by breast development. In males log DHEA-S levels, which increased by Tanner stage, associated positively with pre- and post-BD FEV $1 \%$, pre-BD FVC \%, and negatively (improved) with ACQ6. Patients treated with high-dose inhaled corticosteroids had similar levels of circulating DHEA-S. In females, estradiol levels increased by Tanner stage, and associated negatively with pre-BD FEV $\%$ and FVC \%.

Conclusions: These results support beneficial effects of androgens on lung function and symptom control and weak deleterious effects of estradiol on lung function in children with asthma. Longitudinal data are necessary to confirm these cross-sectional findings and to further elucidate hormonal mechanisms informing sex differences in asthma features with puberty.

Trial registration: ClinicalTrials.gov registration number: NCT01748175.

Keywords: Asthma, Sex hormones, Testosterone, Estradiol, Puberty, Lung function

\footnotetext{
* Correspondence: wgt2p@virginia.edu; WGT2P@hscmail.mcc.virginia.edu

${ }^{1}$ University of Virginia School of Medicine, Charlottesville, VA 22908, USA

Full list of author information is available at the end of the article
}

(c) The Author(s). 2018 Open Access This article is distributed under the terms of the Creative Commons Attribution 4.0 International License (http://creativecommons.org/licenses/by/4.0/), which permits unrestricted use, distribution, and reproduction in any medium, provided you give appropriate credit to the original author(s) and the source, provide a link to the Creative Commons license, and indicate if changes were made. The Creative Commons Public Domain Dedication waiver (http://creativecommons.org/publicdomain/zero/1.0/) applies to the data made available in this article, unless otherwise stated. 


\section{Background}

The prevalence of current asthma in the U.S. is higher in children than in adults, and from pre-school to age 14 years is greater in boys than it is in girls [1]. Both asthma severity and hospitalizations start to decrease in late childhood and remain relatively low into young adulthood [2,3]. After age 18 years, in young men, current asthma prevalence is lower than in childhood; in young women although lower than in childhood, current asthma prevalence is higher than it is in young men, and remains higher in women through middle-age [1]. Surges in endogenous sex hormones across adolescence could affect the "gender switch" in asthma status [2]. For example, DHEA-S, a circulating androgen that increases with puberty, inhibits human airway smooth muscle and airway fibroblast proliferation $[4,5]$ and may influence airway epithelial-to-mesenchymal transition [6]. Testosterone promotes airway smooth muscle relaxation [7]. In women both with and without asthma, $\mathrm{FEV}_{1} \%$ peaks at the end of the luteal phase to the beginning of menstruation, and then decreases when circulating estrogen and progesterone decrease [8]. Accordingly, the fall in circulating estrogen and progesterone from the luteal to the follicular phase of the menstrual cycle is accompanied by a reduction in lymphocyte $\beta_{2}$ adrenoceptor density [9] and increased bronchial responsiveness in women with asthma [10]. Recent studies of dysanapsis (differential growth of airway caliber and lung volume) in healthy subjects suggest that, by adulthood, women develop more small airways resistance than do men [11]. Thus these studies support interdependent effects of sex and endogenous sex hormones on lung growth, and airways responsiveness that likely inform asthma status from puberty to middle-age.

Puberty is a dynamic process regulated by hormonal signals from the central nervous system that results in sexual maturation. Assessment of the stage of pubertal maturation is different in boys than girls [12]. In boys, androgen production gradually increases both from testes producing testosterone and the adrenal glands producing weaker androgens-ultimately leading to pubarche. Girls experience increases in the production of estrogen from the ovaries (driving thelarche and ultimately menarche) and androgens such as androstenedione and DHEA-S from the adrenal glands (driving pubarche in girls) [13]. In children studies of pubertal maturation and asthma status furthermore may be affected by corticosteroid treatment [14]. The primary purpose of the current studies was to do a cross-sectional analysis of the effects of pubertal maturation and sex hormone levels on asthma features in a sample of children enrolled in SARP. We found important differences in phenotypic features according to sex and pubertal stage. In boys higher DHEA-S levels positively associated with greater $\mathrm{FEV}_{1} \%$ predicted and improved 4 week symptoms, whereas in girls, breast development, signifying estradiol effects, weakly associated with lower lung function.

\section{Methods \\ Severe asthma research program}

Details of the SARP III network, recruitment targets, enrollment and characterization procedures, and the longitudinal protocol have been previously published $[15,16]$. Active tobacco smokers were excluded. Participants maintained medications for asthma as prescribed by their care provider. Study procedures were approved by the IRB at each institution and an independent Data Safety Monitoring Board (Additional file 1: Figure S1). All subjects provided written informed consent and/or assent. The study is listed on ClinicalTrials.gov.

\section{Criteria for enrollment}

Enrollees met criteria for current asthma based on responsiveness to $\beta$-agonist $\left(\geq 12 \%\right.$ increase in $\mathrm{FEV}_{1}$ from baseline post-albuterol) and/or positive methacholine bronchoprovocation. Severe asthma was defined according to the ERS/ATS consensus definition [17]. Children whose asthma required treatment with high-dose inhaled corticosteroids $(\geq 440 \mathrm{mcg}$ of fluticasone equivalents per day for children $6-11$ years of age; $\geq 880 \mathrm{mcg}$ fluticasone equivalents per day $\geq 12$ years of age) plus a second controller and/or systemic corticosteroids to maintain asthma control or which was uncontrolled despite these medications were assigned to the severe sub-group. Medications at this level were required for at least 6 of the previous 12 months and the 3 months prior to enrollment for participants to qualify for the severe sub-group. Those who did not meet criteria for severe asthma were assigned to the non-severe sub-group.

\section{Characterization}

Characterization procedures extended from the SARP I and II protocols [18-20] for SARP III included detailed history and physical examination, vital signs, height, weight, characterization questionnaires, assessment of four-week symptom control (asthma control questionnaire; ACQ6 [21]), and spirometry with maximal $\beta$-agonist reversibility testing (dose escalation protocol at $180 \mathrm{mcg}$ albuterol increments up to $720 \mathrm{mcg}$ ).

Blood was drawn during the visit but not with systematic timing related to the timing of the spirometry. Pubertal stage was determined by study coordinators and investigators certified a priori to enrollment by a pediatric endocrinologist (MDD) with the method of Marshall and Tanner [12]. To identify central (CNS) puberty, Tanner stage for males was based on pubic hair and for females breast development. Females were also separated into pre-/early adrenarche and mid-/late adrenarche based on Tanner stages of pubic hair. 
Spirometry, maximum bronchodilator challenge and methacholine challenge were performed by study coordinators certified after standard training and completion of an examination administered by the SARP III Data Coordinating Center on ATS-compatible equipment. Quality analysis of lung function tests and validation of results was accomplished by inspection of randomly sampled flow volume plots by a central over-reader. Population reference standards adjusted for age, height, and sex were from the Global Lung Initiative (GLI) [22].

\section{Sex hormone assays}

Sex hormone and SHBG levels were analyzed at the University of Virginia Center for Research in the Reproduction Ligand Core Laboratory. Estradiol levels were assessed with Calbiotech ELISA and all other metabolites were assessed using the Siemens Immulite 2000. Free testosterone was calculated from total testosterone and SHBG as previously described [23]. The lower limit of detection for assays were: testosterone $20 \mathrm{ng} / \mathrm{dL}$; DHEAS $15 \mu \mathrm{g} / \mathrm{dL}$; progesterone $0.20 \mathrm{ng} / \mathrm{mL}$; and SHBG $10 \mathrm{nmol} /$ L. For the purpose of mathematical analyses, individuals with measurements below the limit of detection were counted as having a value just below the lower limit of detection. Intra-/inter-assay coefficients of variation (CVs, $\%$ ) were as follows: estradiol 6.3/8.1, testosterone 4.4/7.5, DHEAS 5.4/6.5, progesterone 4.4/7.8, and SHBG 2.7/5.2.

\section{Data analysis}

The analysis was restricted to enrollees with complete data sets with regards to Tanner stage and lung function. Because of natural variation in recruitment, mid-Tanner stages were relatively under-represented (Table 1 ). To examine the effects of pubertal maturation, participants were assigned to sub-groups including those with pre-/early puberty (Tanner 1-2) and mid-late puberty (Tanner 3-5).

Categorical data are presented as count and percentage, and continuous data as means \pm standard deviations. Comparisons of differences by pubertal stage between males and females (both adrenarche and breast development) was performed by testing the stage by sex interaction term in a simple regression model. $\mathrm{PC}_{20}$ was evaluated on a log base 2 scale, with two zero values replaced by 0.016 , or half of the minimum non-zero value. Univariable linear regression was used to evaluate relationships between measures of lung function or ACQ6 and individual 5-level Tanner stage. Multivariable linear regression tested associations of clinical outcomes (lung function and ACQ6) with sex hormone levels (for males, testosterone and DHEA-S; for females, estradiol, progesterone, free testosterone and DHEAS) as co-variates. With a backward selection method, hormones that were not significantly associated with the outcome were removed in steps and only significant associations were reported. These analyses were then further stratified based on BMI $\geq 85$ th percentile and $<85$ th percentile. $P$-values are unadjusted in these exploratory post hoc analyses.

\section{Results \\ Sample features}

The sample included 116 males and 71 females (Table 1). There were no significant differences between males and females with regard to age, racial/ ethnic background, asthma severity, or corticosteroid treatment. There were 110 severe and 77 non-severe participants in the analytic cohort. Of these, 74 severe- and 30 non-severe participants had an ACQ $<1.0$ as an estimate of poor control $(67 \%$ and $39 \%$, respectively) [24]. Overall the sample was enriched in African Americans and severe asthma, with a high proportion with atopic sensitization. Among males, 84 (63\%) were in pre-/early puberty and $32(28 \%)$ in mid-/late puberty by Tanner stages of pubic hair development. Among females, 32 (45\%) were in pre-/early puberty and $39(56 \%)$ in mid-/late puberty by Tanner stages of breast development. 37 females (52\%) were in pre-/early- and 34 (47\%) in mid-/late adrenarche by Tanner stages of pubic hair. Adolescent females discordant for breast and pubic hair stages of development included 6 wherein pubic hair stage exceeded breast stage, and 1 wherein breast stage exceeded pubic hair (Additional file 1: Table S1).

\section{Differences in sex hormones with puberty}

68 children in the sample had circulating sex hormones measured (45 males, 23 females). From pre-/early to mid -/late puberty, testosterone increased in males, and estradiol increased in females (Additional file 1: Figure S2A and B). Likewise with puberty DHEA-S increased in males and DHEA-S, progesterone, and free testosterone increased in females (results not shown).

\section{Differences in lung function with puberty}

For males, there was a tendency for lung function and the maximum bronchodilator response to improve with pubertal maturation, but these differences were not statistically significant (Table 2). By contrast in females, both the post-bronchodilator $\mathrm{FEV}_{1} \%$ and $\mathrm{FVC} \%$ were significantly lower (by $8.9 \%$ and $9.1 \%$ respectively, $p=0.01$ each) from pre-/early to mid-/late puberty as determined by breast development. In an analysis limited to severe females alone $(n=44)$, the lower $\mathrm{FEV}_{1}$ (\%) from early to late puberty remained significant. Similarly, the differences by pubertal maturation remained when participants were stratified by overweight/obesity status (Additional file 1: Table S2-A-1 and S2-A-2). These differences by Tanner stage are attributable to breast and not pubic hair development, supporting a likely estradiol effect. 
Table 1 SARP III Pediatric sample features compared by sex

\begin{tabular}{|c|c|c|c|c|}
\hline & $\begin{array}{l}\text { Males } \\
(n=116)\end{array}$ & $\begin{array}{l}\text { Females } \\
(n=71)\end{array}$ & & $P$ value \\
\hline Age, years, mean $( \pm \mathrm{sd})$ & $11.3( \pm 2.7)$ & $11.8( \pm 3.1)$ & & 0.21 \\
\hline Age of asthma diagnosis & $3.1( \pm 2.7)$ & $3.1( \pm 2.7)$ & & 0.90 \\
\hline Years since onset of asthma symptoms (asthma duration) & $9.0( \pm 3.2)$ & $9.4( \pm 3.5)$ & & 0.50 \\
\hline BMI percentile & $76.9( \pm 26.5)$ & $73.5( \pm 27.1)$ & & 0.40 \\
\hline \multicolumn{5}{|l|}{ Race/ethnicity, n (\%) } \\
\hline White non-Hispanic & $28(24)$ & $26(37)$ & & 0.26 \\
\hline African American non-Hispanic & $51(44)$ & $26(37)$ & & \\
\hline Hispanic & $17(15)$ & $11(15)$ & & \\
\hline Other & $20(17)$ & $8(11)$ & & \\
\hline \multicolumn{5}{|l|}{ Asthma severity, n (\%) } \\
\hline Severe & $66(57)$ & $44(62)$ & & 0.49 \\
\hline Not severe & $50(43)$ & $27(38)$ & & \\
\hline Systemic Corticosteroid Treatment (current) & $11(9)$ & $5(7)$ & & 0.56 \\
\hline Systemic Corticosteroid Treatment (past 3 mos) & $7(6)$ & $3(4)$ & & 0.59 \\
\hline High-Dose Inhaled Corticosteroids & $82(71)$ & $50(70)$ & & 0.97 \\
\hline Low-Medium-Dose Inhaled Corticosteroids & $23(20)$ & $14(20)$ & & 0.99 \\
\hline Montelukast (during last 12 months) n(\%) & $71(60)$ & $54(76)$ & & 0.03 \\
\hline Long-acting beta agonist & $86(74)$ & $49(69)$ & & 0.45 \\
\hline \multicolumn{5}{|l|}{ Atopic sensitization } \\
\hline At Least One Positive Specific IgE (of 15 tests) & $106(93)$ & $64(91)$ & & 0.70 \\
\hline Number of Positive Specific lgEs (of 15 tests). Mean ( \pm sd) & $7.0(4.3)$ & $7.0(4.9)$ & & 0.95 \\
\hline History of atopic dermatitis. $n(\%)$ & $74(64)$ & $44(62)$ & & 0.80 \\
\hline \multirow[t]{2}{*}{ Tanner stage, n (\%) } & Males & Females & & \\
\hline & Pubic hair & Breast development & Pubic hair & \\
\hline । & $67(58)$ & $14(20)$ & $24(34)$ & \\
\hline$\|$ & $17(15)$ & $18(25)$ & $13(18)$ & \\
\hline III & $8(7)$ & $16(23)$ & $8(11)$ & \\
\hline IV & $7(6)$ & $9(13)$ & $13(18)$ & \\
\hline V & $17(15)$ & $14(20)$ & $13(18)$ & \\
\hline
\end{tabular}

\section{Differences in ACQ6 with puberty}

With regards to four week symptom control (Table 3), with males $(n=116)$ the ACQ6 was not significantly different from pre-/early to mid-/late puberty, whereas in females $(n=71)$ the ACQ6 was higher (worse) with puberty assessed by breast bud $(p<0.05)$ and by pubic hair development $(p<0.05)$. In males with severe but not non-severe asthma, the ACQ6 was lower (improved) with pubertal maturation, whereas the ACQ6 was higher with pubertal stage in females with both severe $(n=44)$ and non-severe $(n=37)$ asthma $(p<0.05$ for both). Again, the differences by pubertal maturation remained when participants were stratified by overweight/obesity status (Additional file 1: Table S2-B-1 and S2-B-2).

\section{Multi-variable linear regression of lung function and ACQ6 with sex hormones Males}

For males in the sample 6-18 years of age, lung function associated positively with log DHEA-S values (Table 4). The pre-bronchodilator $\mathrm{FEV}_{1} \%(\beta=8.05 ; p=0.01)$, post-BD $\mathrm{FEV}_{1} \%(\beta=8.82, p=0.008)$, and pre-BD FVC $\%(\beta=8.33$, $p=0.01$ ) had strongly positive $\beta$ coefficients. The ACQ6 had a negative $\beta$ coefficient with higher log DHEA-S values ( $\beta=-0.59, p=0.007)$, indicating 4 week symptom improvement. These associations were driven largely by participant who were overweight/obese (Additional file 1: Table S3-A-1 and S3-A-2). The final model predicting ACQ6 included negative $\beta$ coefficients for both log DHEA-S and testosterone, as well as the interaction of log DHEA-S with 


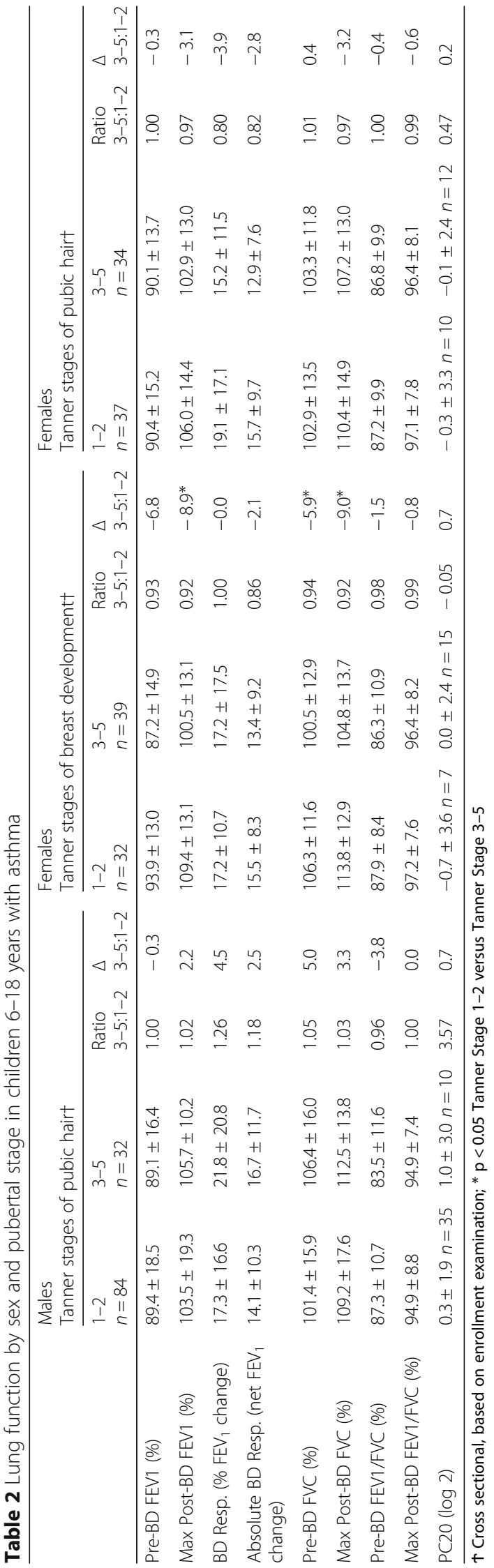




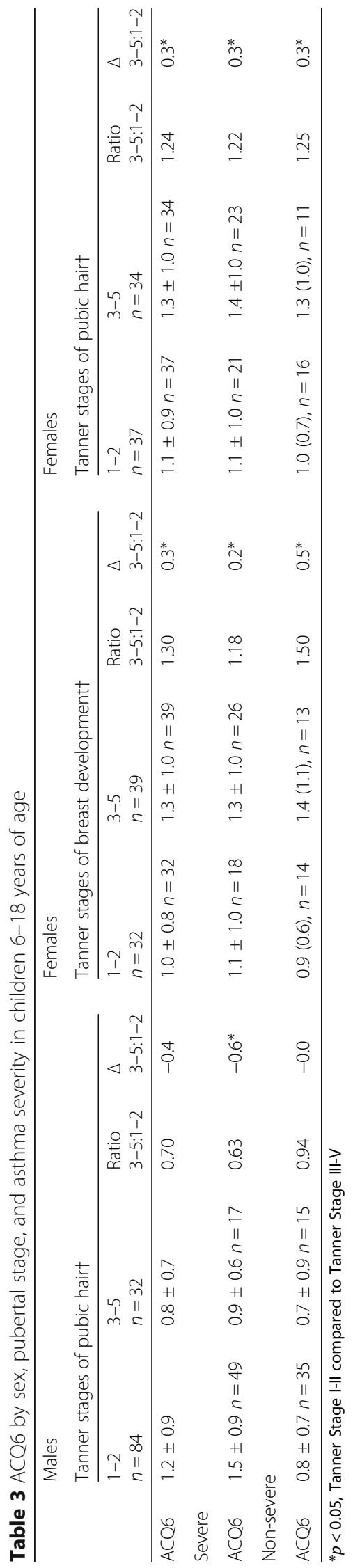


Table 4 Linear regression analysis of lung function and ACQ6 by sex hormone levels in males 6-18 years with asthma

\begin{tabular}{|c|c|c|c|c|c|}
\hline Outcome variable & Covariate remaining in the model* & Beta coefficient & Covariate $p$ value & R squared & $P$ value of the model \\
\hline Pre-BD FEV ${ }_{1}(\%)$ & Log (DHEA-S) & 9.285 & 0.011 & 0.168 & 0.011 \\
\hline Post-BD FEV 1 (\%) & $\log (\mathrm{DHEA}-\mathrm{S})$ & 9.527 & 0.006 & 0.160 & 0.006 \\
\hline Pre-BD FVC (\%) & $\log (\mathrm{DHEA}-\mathrm{S})$ & 9.121 & 0.007 & 0.157 & 0.007 \\
\hline \multirow[t]{3}{*}{ ACQ6 } & $\log (\mathrm{DHEA}-\mathrm{S})$ & -0.008 & 0.019 & 0.214 & 0.018 \\
\hline & Testosterone & -0.005 & 0.031 & & \\
\hline & $\log ($ DHEA-S) *Testosterone \# & 0.003 & 0.05 & & \\
\hline
\end{tabular}

${ }^{*}$ Results reflect final results of a model that started with testosterone and DHEA-S. Covariates that were not significantly associated with the outcome in this model were then removed by backward selection and model was re-run with remaining variables. \# A log (DHEA-S) * testosterone interaction was found and included in the final model

testosterone, an association not present when the cohort was stratified by overweight/obesity status. Circulating DHEA-S levels in males did not vary significantly when compared according to treatment with high-dose versus medium-dose inhaled corticosteroids (Additional file 1: Figure S3).

\section{Females}

For females 6-18 years of age, androgens associated positively, but estrogens negatively with lung function (Table 5). Free testosterone had a positive association with post-BD $\mathrm{FEV}_{1} \%(\beta=3.99, p=0.04)$. In contrast, estradiol had negative $\beta$ coefficients for pre-BD $\mathrm{FEV}_{1} \%(\beta=-0.47, p=0.03)$, post-BD $\mathrm{FEV}_{1} \%(\beta=-0.62, p=0.0009)$, pre-BD FVC $\%$ $(\beta=-0.36, p=0.04)$, and post-BD FVC $\%(\beta=-0.33$, $p=0.03)$. These associations were not significant in either group when stratified by overweight/obesity status (Additional file 1: Table S3-B-1 and S3-B-2). For the ACQ6, only log DHEA-S had a significant association, it varied positively $(\beta=0.49, p=0.05)$ and the correlation was relatively weak. ACQ6 was not associated with age (Additional file 1: Table S4).

\section{Discussion}

In children enriched in severe asthma enrolled in the NIH/ NHLBI SARP III study $(n=187)$, there were important differences in lung function and four-week symptom control between males and females with pubertal maturation. In males, lung function was not different and symptom control improved when comparing those in early vs. late puberty, whereas in females lung function and symptom control were worse. Circulating sex hormones changed with puberty; in males greater androgen levels associated with better lung function and ACQ6, while in females greater circulating estrogens had a weak but significant negative association with lung function. These results support the general hypothesis that with pubertal maturation asthma severity is likely to improve in males but worsen in females [2]. Furthermore our data suggest a beneficial effect of endogenous androgens on lung function growth and ACQ6 in males in later puberty; and that endogenous estrogens may have weak deleterious effects on lung function growth in girls.

A beneficial effect of androgens is suggested by the presence of fewer asthma symptoms in late Tanner stage males with severe asthma. In females the presence of more asthma symptoms in late adolescence either reinforces the benefit of androgens (given an absence of significant androgens in females) or supports a negative role for estradiol. These integrated, Tanner-stage-based measurements of the effect of sex hormones over time are complemented by the association between DHEA-S and fewer asthma symptoms (lower ACQ6) and higher pre- and postalbuterol FEV1\% observed in boys. Given that GLI-based normal ranges of lung function are age-specific these maturational and hormone-associated measures appear to be present beyond the expected changes in lung function based on age alone. Furthermore, we did not note associations between ACQ6 and age in either boys or girls. Note that it is unlikely that the level of corticosteroid therapy

Table 5 Multi-variable regression analysis of lung function and ACQ6 by sex hormone levels in females 6-18 years with asthma

\begin{tabular}{llllll}
\hline Outcome variable & Covariate remaining in the model* & Beta coefficient & Covariate $p$ value & R squared & $P$ value of the model \\
\hline Pre-BD FEV ${ }_{1}(\%)$ & Estradiol & -0.457 & 0.028 & 0.209 & 0.028 \\
Post-BD FEV ${ }_{1}(\%)$ & Estradiol & -0.454 & 0.005 & 0.320 & 0.005 \\
Pre-BD FVC (\%) & Estradiol & -0.351 & 0.025 & 0.217 & 0.025 \\
Post-BD FVC (\%) & Estradiol & -0.322 & 0.015 & 0.249 & 0.015 \\
ACQ6 & log (DHEA-S) & 0.006 & 0.048 & 0.173 & 0.048 \\
\hline
\end{tabular}

*Results reflect final results of a model that started with log (DHEA-S), estradiol, progesterone, and free testosterone as covariates. Covariates that were not significantly associated with the outcome in this model were then removed by backward selection and model was re-run with remaining variables 
caused the male/female discordance we observed because the males and females did not differ with regard to oral or inhaled corticosteroid dosing (Table 1). Furthermore treatment with high-dose corticosteroids did not suppress DHEA-S levels in males. Although the testosterone increase is quantitatively orders of magnitude greater than that of DHEA-S with puberty $[25,26]$, DHEA-S levels in our analysis were more strongly associated with better lung function and improved ACQ6 than was testosterone.

Of note, androgen receptors are expressed in bronchial smooth muscle tissue, and testosterone relaxes contracted airway smooth muscle, suggesting a beneficial effect of androgens on airway smooth muscle tone [7]. Additionally, DHEA-S inhibits human airway smooth muscle and airway fibroblast proliferation [5], and may influence airway epithelial-to-mesenchymal transition [6], suggesting that androgens may prevent adverse airway remodeling seen in severe asthma. Together, these affects could be associated with the lower asthma symptom scores we observed in association with increased DHEA-S and with late adolescence. Indeed a trial of androgen administration provided early data regarding safety and improved ACQ [27]. We noted associations between DHEA-S and lung function that were present in overweight/obese but not normal weight. This differential effect by weight status, which was seen only in boys, is of unclear significance and requires further investigation.

In females, subtle but significant discordance between loss of lung function observed in association with late puberty assessed by breast staging relative to pubic hair staging suggests that estrogen, which drives breast development, may be the main factor affecting lung function. Only females have a surge of estrogen or progesterone during puberty, and breast development is exclusively associated with this surge [28]. In our study the number of females with discordant pubertal examinations was small, whereas adrenal androgen effects confounded all assessments. We also cannot exclude an adverse effect of progesterone. For example, the effects of pregnancy on lung function may be either both estrogen and progesterone-dependent, and both hormones have been hypothesized to play roles in the worsening of lung function [2].

These results likewise support disparate changes in lung growth between males and females with puberty that bear on the remarkable decline in hospitalizations and asthma severity seen in young adults [3]. Asthma prevalence appears to decline more in males than it does in females by the second decade of life [1], a result which might be explained by disparate trends in airway growth due to sex hormones. Young adult females exhibit a "dysanaptic" pattern of airway growth which supports a pattern of anatomically "fixed" airflow limitation [11]. With regards to airway hyperreactivity, we found that the level of methacholine responsiveness actually fell in both males and females with Tanner stage, a finding differs from the results of Tantisera et al. [29] wherein females had increased methacholine responsiveness. The difference between the two studies may be due to sample differences, wherein the SARP III cohort is relatively enriched with African Americans and children with severe asthma.

It should also be noted that other hormonal changes during puberty could also affect lung function, including an increase in the degree of insulin resistance [30] - which itself is associated with increased risk of asthma in adults [31] and adolescent girls [32] - and elevations in stress hormones, including cortisol [33] -with such stress systems further associated with asthma risk [34]. While temporally related (i.e., during puberty), the processes of insulin resistance and stress response go beyond sex hormone regulation alone [30, 33]. Unfortunately, the timing of our blood collection was not specifically in the early morning (thus not as helpful to assess cortisol regulation) or with fasting status (for assessing insulin resistance), and thus we were not able to assess how these processes may have interacted with changes in sex hormones. Nevertheless, because we were able to assess relationships between measured levels of sex steroids and outcomes important to asthma severity, our findings suggest a direct role for sex steroids themselves.

This cross-sectional analysis of the effects of puberty on asthma features is exploratory and intended primarily to identify specific hypotheses to be tested with longitudinal measurements. We would point out that the veracity of the results is limited by the cross-sectional analytic approach, and the relative paucity of children who were in the mid-Tanner stages (III/IV) at the time of enrollment and our lack of knowledge for most female participants of whether central puberty or adrenarche began first. We lacked data on some participant characteristics, including depression status-which could affect stress response [34] - and the fraction of excreted nitrosoxide (FeNO)-which would have permitted assessment of the relationship between hormone levels with activity of Th2-high airway inflammation.

\section{Conclusions}

These results impact understanding of the differences in asthma features with pubertal maturation and the potential for new treatment. The androgen surge with puberty is likely to confer protective effects on lung growth in both males and females whereas estrogens may well have deleterious effects in females extending into adult development. A trial of weak androgen therapy in adolescent children with low androgen levels and poorly-controlled asthma could be considered to improve lung function. These data may help to explain the gender switch observed in asthma incidence during adolescence and likewise inform lung growth and asthma severity with subsequent maturation into adulthood. 


\section{Additional file}

Additional file 1: Sex Hormones \& Asthma. Type of data: Tables and Figures. (DOCX $468 \mathrm{~kb})$

\section{Abbreviations \\ ACQ6: Asthma control questionnaire 6 item scale; DHEA- \\ S: Dehydroepiandrostenedione sulfate; $\mathrm{FEV}_{1} \%$ : Forced expired volume in one second percent predicted; FVC \%: Forced expired vital capacity \% predicted; NIH/NHLBI: National Institutes of Health/National Heart Lung Blood Institute; SARP: Severe Asthma Research Program}

\section{Acknowledgments}

The authors wish to acknowledge the children and their parents who participated in the SARP III study, as well as the hard work of the site-based study coordinators and regulatory personnel, the oversight of the members of the Data Safety and Monitoring Board, and the diligent efforts of the $\mathrm{NIH}$ / NHLBI project officers and staff who administered the protocol.

SARP Principal/Co-Principal Investigators.

Eugene R. Bleecker, PI, Wake Forest University, U10 HL109164.

Mario Castro, PI, Washington University, U10 HL109257.

John V. Fahy, PI, University of California San Francisco, U10 HL109146.

Elliot Israel and Bruce Levy, Co-PI's, Brigham and Women's Hospital, U10 HL109172.

Benjamin Gaston, Pl, Rainbow Babies and Children's Hospital Virginia-Cleveland Consortium, U10 HL109250.

Serpil Erzurum, Co-PI, Cleveland Clinic, Virginia-Cleveland Consortium, U10 HL109250.

W. Gerald Teague, Co-PI, Univ. of Virginia, Virginia-Cleveland Consortium, U10 HL109250.

Nizar N. Jarjour, PI, University of Wisconsin, U10 HL109168.

Sally E. Wenzel, Pl, University of Pittsburgh, U10 HL109152.

David T. Mauger, PI, DCC, Penn State University, U10 HL109086-04.

\section{Funding}

This work was supported by the following grants: U10 HL109164, U10 HL109257, U10 HL109146, U10 HL109172, U10 HL109250, U10 HL109250,

U10 HL109250, U10 HL109168, U10 HL109152, U10 HL109086-04.

\section{Availability of data and materials}

The datasets generated and/or analyzed during the current study are not currently publicly available but will be made available following completion of ongoing data collection. Contact: David T. Mauger, PhD, Pennsylvania State University School of Medicine, DMauger@phs.psu.edu.

\section{Authors' contributions}

BMG, MDD, WGT, BRP, ERB, MC, JVF, El, BL, SCE, NNJ, SEW, and DTM devised the present study and/or the data analysis. BMG, WGT, ERB, MC, JVF, El, BL, SCE, NNJ, SEW, AMF, RM, KRR, JC, MJL, MP, NPL, MLF, FH, WCM, SPP, DM,

$A M C, L B B, R L S, S R, A M I, W P$ and JMG were involved in participant recruitment and/or assessment. BRP performed the statistical analysis. MDD BMG drafted the preliminary manuscript and WGT drafted the final version. All authors read and approved the final manuscript.

\section{Ethics approval and consent to participate}

Study procedures were approved by the IRB at each institution and an independent Data Safety Monitoring Board. All subjects provided written informed consent and/or assent. For participants under 16 years-old consent was provided by a parent or legal guardian.

\section{Competing interests}

There are no conflicts of interest with the study sponsors (NIH/NHLBI) or any commercial entity in the study design, the collection, analysis, and interpretation of the data, the writing of the report, and the decision to submit the paper for publication. The authors submit they will declare potential conflicts of interests per BMC Pulmonary Medicine publication policies.

\section{Publisher's Note}

Springer Nature remains neutral with regard to jurisdictional claims in published maps and institutional affiliations.

\section{Author details}

'University of Virginia School of Medicine, Charlottesville, VA 22908, USA. ${ }^{2}$ Pennsylvania State University School of Medicine, Hershey, USA. ${ }^{3}$ Lerner Research Institute, Cleveland Clinic Foundation, Cleveland, USA. ${ }^{4}$ Emory University School of Medicine, Atlanta, USA. ${ }^{5}$ Rainbow Babies and Children's Hospital, Cleveland, USA. ${ }^{6}$ San Francisco School of Medicine, University of California, San Francisco, USA. 'University of Pittsburgh School of Medicine, Pittsburgh, USA. ${ }^{8}$ Wake Forest University School of Medicine, Winston-Salem, USA. ${ }^{9}$ Washington University School of Medicine, St. Louis, USA. ${ }^{10}$ University of Wisconsin School of Medicine, Madison, USA. ${ }^{11}$ Virginia Commonwealth University School of Medicine, Richmond, USA. ${ }^{12}$ Harvard University School of Medicine, Boston, USA.

Received: 31 July 2017 Accepted: 9 March 2018

Published online: 10 April 2018

\section{References}

1. National Center for Environmental Health, Division of Environmental Hazards and Health Effects, Centers for Disease Control and Prevention, Asthma Surveillance Data. www.cdc.gov/asthma/asthmadata.htm. Accessed 1 Feb 2018.

2. Zein JG, Erzurum SC. Asthma is Different in Women. Curr Allergy Asthma Rep. 2015;15(6):28.

3. Zein JG, Udeh BL, Teague WG, Koroukian SM, Schlitz NK, Bleecker ER, et al. Impact of age and sex on outcomes and hospital cost of acute asthma in the United States, 2011-2012. PLoS One. 2016;11(6):e0157301.

4. Koziol-White CJ, Goncharova EA, Cao G, Johnson M, Krymskaya VP, Panettieri RA. DHEA-S inhibits human neutrophil and human airway smooth muscle migration. Biochim Biophys Acta. 2012;1822(10):1638-42.

5. Mendoza-Milla C, Valero Jiménez A, Rangel C, Lozano A, Morales V, Becerril $C$, et al. Dehydroepiandrosterone has strong antifibrotic effects and is decreased in idiopathic pulmonary fibrosis. Eur Respir J. 2013;42(5):1309-21.

6. Xu L, Xiang $X$, Ji X, Wang W, Luo M, Luo $S$, et al. Effects and mechanism of dehydroepiandrosterone on epithelial-mesenchymal transition in bronchial epithelial cells. Exp Lung Res. 2014:40(5):211-21.

7. Kouloumenta V, Hatziefthimiou A, Paraskeva E, Gourgoulianis K, Molyvdas PA. Non-genomic effect of testosterone on airway smooth muscle. $\mathrm{Br}$ ] Pharmacol. 2006;149(8):1083-91.

8. Farha S, Asosingh K, Laskowski D, Hammel J, Dweik RA, Wiedemann HP, Erzurum SC. Effects of the menstrual cycle on lung function variables in women with asthma. Am J Respir Crit Care Med. 2009;180:304-10.

9. Wheeldon NM, Newnham DM, Coutie WJ, Peters A, McDevitt DG, Lipworth BJ. Influence of sex-steroid hormones on the regulation of lymphocyte $\beta_{2}$ adrenoceptors during the menstrual cycle. Br J Clin Pharmacol. 1994:37:583-8.

10. Tan KS, McFarlane LC, Lipworth BJ. Loss of normal cyclical $\beta_{2}$ adrenoceptor regulation and increased premenstrual responsiveness to adenosine monophosphate in stable female asthmatic patients. Thorax. 1997;52(7):608-11.

11. Sheel AW, Dominelli PB, Molgat-Seon Y. Revisiting dysanapsis: sex-based differences in airways and the mechanics of breathing during exercise. Exp Physiol. 2016;101(2):213-8.

12. Marshall WA, Tanner JM. Variations in the pattern of pubertal changes in girls. Arch Dis Childhood. 1969:44:291-303.

13. Mouritsen A, Søeborg T, Hagen CP, Mieritz MG, Johannsen TH, Frederiksen $\mathrm{H}$, Andersson AM, Juul A. Longitudinal changes in serum concentrations of adrenal androgen metabolites and their ratios by LC-MS/MS in healthy boys and girls. Clin Chim Acta. 2015;450:370-5.

14. Dorsey MJ, Cohen LE, Phipatanakul W, Denufrio D, Schneider LC. Assessment of adrenal suppression in children with asthma treated with inhaled corticosteroids: use of dehydroepiandrosterone sulfate as a screening test. Ann Allergy Asthma Immunol. 2006;97(2):182-6.

15. Denlinger L, Ramratnam S, Ross K, Phillips BR, Bhakta NR, Cardet JC, Castro M, Peters SP, Phipatanakul W, Aujla S, Bacharier LB, Bleecker ER, Comhair SAA, Coverstone A, DeBoer M, Erzurum SC, Fain SB, Fajt M, Fitzpatrick AM, Gaffin J, Gaston B, Hastie AT, Hawkins GA, Holguin F, Irani AM, Israel E, Levy BD, Ly N, Meyers DA, Moore WC, Myers R, Peters MC, Schiebler ML, Sorkness RL, Teague WG, Wenzel SE, Mauger DT, Fahy JV, Inflammatory JNN. Co- 
morbid features of patients with severe asthma and frequent exacerbations. Am J Respir Crit Care Med. 2017:195:302-13.

16. Phipatanakul W, Mauger DT, Sorkness RL, Gaffin JM, Holguin F, Woodruff PG, Ly NP, Bacharier LB, Bhakta NR, Moore WC, Bleecker ER, Hastie AT, Meyers DA, Castro M, Fahy J, Fitzpatrick A, Gaston BM, Jarjour NN, Levy BD, Peters SP, Teague WG, Fajt M, Wenzel SE, Erzurum SC, Israel E. The severe asthma research program. Effects of age and disease severity on systemic corticosteroid responses in asthma. In press. Am J Respir Crit Care Med. 2017;195(11):1439-48.

17. Chung KF, Wenzel SE, Brozek JL, Bush A, Castro M, Sterk P, Adcock IM, Bateman E, Bel E, Bleecker E, Boulet LP, Brightling C, Chanez P, Dahlen SE, Djukanovic R, Frey U, Gaga M, Gibson P, Hamid Q, Jarjour N, Mauad T, Sorkness R, Teague WG, International ERS. ATS consensus definition, mechanisms, evaluation and treatment of severe asthma. Eur Respir J. 2014;43(2):343-73.

18. Moore WC, Bleecker ER, Curran-Everett D, Erzurum SC, Ameredes BT, Bacharier $L$, et al. Characterization of the severe asthma phenotype by the National Heart, Lung, and Blood Institute's severe asthma research program. J Allergy Clin Immunol. 2007;119(2):405-13.

19. Moore WC, Meyers DA, Wenzel SE, Teague WG, Li H, Li X, et al. Identification of asthma phenotypes using cluster analysis in the severe asthma research program. Am J Respir Crit Care Med. 2010;181(4):315-23.

20. Fitzpatrick AM, Teague WG, Meyers DA, Peters SP, Li X, Li H, et al. Heterogeneity of severe asthma in childhood: confirmation by cluster analysis of children in the National Institutes of Health/National Heart, Lung, and Blood Institute Severe Asthma Research Program. J Allergy Clin Immunol. 2011:127(2):382-9. e381-313

21. Juniper EF, Svensson K, Mork A, Stahl E. Measurement properties and interpretation of three shortened versions of the asthma control questionnaire. Respir Med. 2005;99:553-8.

22. Quanjer PH, Stanojevic S, Cole TJ, Baur X, Hall GL, Culver BH, Enright PL, Hankinson JL, Ip MSM, Zheng J, Stocks J. Multi-ethic reference values for spirometry for the 3-95 year age range: the global lung function 2012 equations. Eur Respir J. 2012;40:1324-43.

23. Vermeulen A, Verdonck L, Kaufman JM. A critical evaluation of simple methods for the estimation of free testosterone in serum. J Clin Endocrinol Metab. 1999;84(10):3666-72.

24. Juniper EF, Bousquet J, Abetz L, Bateman ED, Committee G. Identifying 'well-controlled' and 'not well-controlled' asthma using the asthma control questionnaire. Respir Med. 2006;100:616-21.

25. Chen F, Knecht K, Birzin E, Fisher J, Wilkinson H, Mojena M, et al. Direct agonist/antagonist functions of dehydroepiandrosterone. Endocrinology. 2005;146(11):4568-76.

26. Gao W, Bohl CE, Dalton JT. Chemistry and structural biology of androgen receptor. Chem Rev. 2005;105(9):3352-70.

27. Wenzel SE, Robinson CB, Leonard JM, Panettieri RA. Nebulized dehydroepiandrosterone-3-sulfate improves asthma control in the moderate-to-severe asthma results of a 6-week, randomized, double-blind, placebo-controlled study. Allergy Asthma Proc. 2010;31(6):461-71.

28. Palmert MR, Dunkel L. Clinical practice. Delayed puberty. N Engl J Med. 2012:366(5):443-53.

29. Tantisira KG, Colvin R, Tonascia J, Strunk RC, Weiss ST, Fuhlbrigge AL, et al. Airway responsiveness in mild to moderate childhood asthma: sex influences on the natural history. Am J Respir Crit Care Med. 2008;178(4):325-31.

30. Goran MI, Gower BA. Longitudinal study on pubertal insulin resistance. Diabetes. 2001;50:2444-50.

31. Thuesen BH, Husemoen LL, Hersoug LG, Pisinger C, Linneberg A. Insulin resistance as a predictor of incident asthma-like symptoms in adults. Clin Exp Allergy. 2009;39:700-7.

32. Kozyrskyj AL, Zeng Y, Saurek-Aleksandrovska N, Sellers EA, Ramsey CD, Becker AB. Insulin resistance, puberty, and nonatopic asthma in adolescent girls. Am J Respir Crit Care Med. 2014;190:474-7.

33. Gunnar MR, Wewerka S, Frenn K, Long JD, Griggs C. Developmental changes in hypothalamus-pituitary-adrenal activity over the transition to adolescence: normative changes and associations with puberty. Dev Psychopathol. 2009;21:69-85.

34. Bahreinian S, Ball GD, Vander Leek TK, Colman I, McNeil BJ, Becker AB, Kozyrskyj AL. Allostatic load biomarkers and asthma in adolescents. Am J Respir Crit Care Med. 2013;187:144-52.

\section{Submit your next manuscript to BioMed Central and we will help you at every step:}

- We accept pre-submission inquiries

- Our selector tool helps you to find the most relevant journal

- We provide round the clock customer support

- Convenient online submission

- Thorough peer review

- Inclusion in PubMed and all major indexing services

- Maximum visibility for your research

Submit your manuscript at www.biomedcentral.com/submit
Biomed Central 